SCHOLARS: Journal of Arts \& Humanities

Volume 2, August 2020, pp. 83-90

[Peer-Reviewed, Open Access, Indexed in NepJOL]

Print ISSN: 2773-7829; e-ISSN: 2773-7837

DOI: https://doi.org/10.3126/sjah.v2i0.35016

Central Department of English

Tribhuvan University

Kirtipur, Kathmandu, Nepal

www.cdetu.edu.np/ejournal/

Review Article

\title{
Epistemological Values and Limitations of Ethnography as an Interpretive Research Approach
}

\author{
Youba Raj Luintel, PhD \\ Central Department of Sociology \\ Tribhuvan University, Kirtipur, Kathmandu, Nepal
}

\begin{abstract}
The research method in humanities and social sciences shares a certain theoretical frame and research design with the interpretive approach. The "interpretive approach" of ethnographic research brings humanities and social sciences together in the realms of naturalistic inquiry as well as knowledge production. This article discusses how ethnographers would tend to address these epistemological fronts in scholarship and research design in humanities and social sciences. It also raises some of the pragmatics and methodological utilities of the ethnographic approach, followed by a short description of ethical and practical issues involved in the research process. Both the humanities and social science research adopt the interpretive approach to explore the subject of investigation in the specific theoretical frame and from multiple perspectives. The article concludes that the strengths that it offers, particularly concerning unravelling complexities of people's daily lives in their "meaning perspectives," are unique and appealing even though ethnography never remains immune to some of the limitations of qualitative research.
\end{abstract}

Keywords: Epistemology, ethnography, humanities, interpretive approach, social science

\begin{abstract}
"So, there are three characteristics of ethnographic description: it is interpretive; what it is interpretive of is the flow of social discourse; and the interpreting involved consists in trying to rescue the "said" of such discourse from its perishing occasions and fix it in perusable terms... But there is, in addition, a fourth characteristic of such description, at least as I practice it: it is microscopic."
\end{abstract}

- Clifford Geertz (20-21)

\section{Introduction}

Ethnography is considered a primary method of social and cultural anthropology, but it is also integral to other social sciences and humanities in general. What distinguishes the humanities from other disciplines is its style, a method that is "interpretive." Several academic subjects in humanities and social sciences belong to the “interpretative disciplines.” These disciplines comprise of cultural anthropology, 
Epistemological Values and Limitations of Ethnography 84

communications studies and cultural studies, including languages, law, literature, history and philosophy. They also include the reflection and theory in creative writing, in the performing arts of music, dance and theatre.

The interpretative methodologies of these disciplines are typically distinguished from the positivist and empirical methodologies of the natural and social science disciplines, and the creative and imaginative endeavours of the arts. Such interpretative methodologies, for example, include hermeneutics, literary criticism, phenomenology, and in the discipline of ethnography, which is called as "thick description" (Geertz 6). These theoretical frames are mostly applicable to the study in humanities, especially literature and performance arts. For instance, the phenomenological approach to the text shares its methodological perspectives from ethnography.

Ethnographic accounts can be categorized as more humanistic or social scientific, depending on the orientation and aim of the scholars producing these texts. Ethnography is geared more towards understanding how people create meanings in their lives and what is meaningful to them, and the scholars must use interpretive methods to address the questions. Some ethnographic accounts rely on interpretive methods to explain a given outcome, and have an explanation of causation built into them that are not always explicitly the focus of the study. These orientations in ethnographic accounts fall quite neatly along disciplinary boundaries, at least, in terms of thinking about the social sciences (Murphy 1). In that sense, processes of thinking and reflecting apply both in humanities and social sciences.

In this article, I examine some of the major epistemological challenges against ethnography as posed from quantitative and postmodern corners. I also discuss how ethnographers would tend to address those challenges in the field of research. Moreover, I unfold some of the methodological and practical utilities of the ethnographic approach, followed by a short description of ethical and practical issues involved in the research field of ethnography.

\section{Ethnography: An Overview}

Ethnography is a social scientific description of people and the cultural basis of their "peoplehood" (Vidich and Lyman 25). In research methodology, it is a qualitative approach to "naturalistic" inquiry (Erlandson et al. 5, Lincoln and Guba 251), ${ }^{1}$ the central aim of which is "to understand another way of life from the native point of view" (Spradley 3), for which the researcher participates in people's daily lives for an extended period: watching, listening, and asking. This is how ethnographers attempt to understand the way people make sense of the world in everyday life (Hammersley and Atkinson 243). The researcher, thus, particularly involves in the three major integral activities, such as to observe, to listen and to talk in the ethnographic research.

The researcher can observe people and their cultural practices after looking into those subjects. Looking closely into the subject of study in the field allows the researcher to explore and reflect upon the people and object in the real world. After seeing, looking and observing the subject of studies, such as people, cultures and characters, the

\footnotetext{
${ }^{1}$ Following Delamont (2004) and Hammersley and Atkinson (1995), I use the term "ethnography” in a more liberal way and treat it as an approach, where participant observation and interviewing are considered to be the two prominent methods.
} 
researcher can deduce some conclusions. Moreover, the researcher can involve himself or herself in the field of research. For instance, he or she can participate in feast and festivals of the people to make sense of those people's sense of hospitality, and thus, understand their value system with other people.

An ethnographer both elicits and records narratives as a primary form of field data and rewrites and reconstructs these narratives into polished ethnographic texts (Emerson et al. 352). In this article I argue that ethnography - despite some of its limitations - allows researchers to dissect the complexities of everyday social lives in their natural settings at a deeper level than what conventional survey research can do.

In the following section, I shall shed light on practical and methodological attributes of qualitative research, ones that are unique to ethnography.

\section{Practical and Methodological Attributes of Ethnography}

"Thick description" is the hallmark of ethnographic text (Geertz 29). Thick description is a term used originally by Gilbert Ryle to mean "thinking and reflecting." It gained wider currency in ethnographic literature soon it was used by Clifford Geertz in his seminal work, The Interpretation of Cultures (1973). Ethnography, according to Geertz, contains "inscriptions" of the mundane detail of the everyday setting (188). Ethnography builds such "inscriptions" of thick description (Geertz 7 and 25) through a combination of three strategies: persistent observations, in-depth and open-ended interviews and reflexive diaries (Marshall and Rossman 59).

Qualitative interviews and participant observation are the hallmarks of ethnographic research, issues that I shall discuss, in the following section.

Ethnographic interviews, also called "conversations with a purpose” (Burgess 102), form the backbone of ethnographic research, the other being participant observation (Delamont 205-217, Spradley 122). Because of their open-ended and semi(or, un-)structured design, such interviews effectively enable the researcher to unearth participants' "meaning” and "perspective," and their frames and structures at a deeper and diverse way (Creswell 68-69, Marshall and Rossman 105). Quantitative research in general and a survey questionnaire, in particular, have no such potential which can be filled in with an ethnographic approach.

Since the very work of pioneer ethnographers, such as Malinowski (1922) in anthropology and Whyte (1981) in sociology, there has been a common methodological preference in ethnographic research that ethnographic texts are (or should be) rich and authentic. The richness and authenticity can be maintained only when they are the outcome of a prolonged engagement in the field. It is because of their prolonged engagement in the field that ethnographers often claim of "immersion" in the setting or even "going native" (see Delamont 209). The prolonged engagement allows the researcher build trust and develop a rapport (Erlandson et al. 134) that enhances the quality of the information that they gather, a feature that "quick and rigid" quantitative tools often miss out.

One of the most efficient methodological strategies of ethnographic research is that it values triangulation. The use of multiple sources of data derived from different methods (observation, interviews, tapes, photographs and documents, for instance) and the reiterative nature of data collection in the field allows the researcher to triangulate the 
information gathered (Denzin and Lincoln 7). No other method has this privilege to the extent ethnography has.

The ethnographers often keep a reflexive journal, a kind of diary in which the researcher records information about his or her work to reflect critically (Lincoln and Guba 327; Lincoln and Guba 437). Such diaries are not expected to be systematic and may contain a variety of information, such as a schedule of work, logistics, insights, challenges, hunches, questions, in-site methodological decisions and the larger context in a discrete manner. Still, it supports not only credibility to a research work but also shows dependability and confirmability of the study (Erlandson et al. 35).

Having shed light on the hallmarks of ethnographic research, I shall now discuss some of the epistemological issues that are often posed against the ethnographic research.

\section{Epistemological Challenges}

Although there has been a growing popularity of ethnography in the qualitatively oriented research, at its epistemic level it is still contested whether or not ethnography meets fundamental criteria of "scientific" research. The problem stems from the persistent debates, whether "positivism” or "naturalism” yields better results. Positivism, one of the orthodox and mainstream schools of thought in social sciences, claims that a value-free, detached, uninvolved, thus, an "objective" analysis of social reality is not only possible but it is also superior to other modes of inquiry (see Turner 26, for example). For a positivist, only experimental or quantitative research has the potential to maintain the rigour of "objective" research.

To Brewer, there are two major critiques of ethnography (Brewer 7). First, the natural science critique accuses ethnography of "falling below the standards of science." Second, a postmodern critique that emanates from a humanistic model of social research deconstructs ethnography to its constituent processes and accuses ethnography of “melting into (the) air and dissolving into nothingness” (Brewer 19).

Ethnographers commonly share a belief that the process of sampling is more crucial than the number sampled. A full, detailed and justified description of sampling procedures and decisions -- well reflected in the text -- would reveal how representative the particular research is. It is in this assumption that ethnographers apply purposive sampling to address the concerns over sampling criteria and argue that identification of and engagement with "nested" samples, deliberate hunt for maximum variations and negative instances would help eliminate any biases (Miles and Huberman 31).

Besides, a validity claim (that the research results are a true reflection of the properties or characteristics of the phenomenon observed) is also central in epistemic debates. A methodology of research is considered to be reliable when (and if) it yields similar results against its test in replicable circumstances (time or space). Hence, to prove their validity, the tools or measures being used need to show how reliable and consistent they are. Validity issue, however, applies differently in ethnographic research (Lincoln and Guba 263):

- First, unlike quantitative research, the aim of ethnographic research is not to generalize the findings (from sample to population) or test hypotheses. Ethnographic research always tends to "maximize discovery of the 
heterogeneous patterns and problems that occur in the particular context under study" (Erlandson et al. 82).

- Second, ethnographic (or interpretive) researchers accord value on reflexivity. Ethnographers often use a reflexive journal, peer debriefing, and the audit trail as tools to disclose the "conditions in which (the) understanding has taken place" (Erlandson et al. 140).

Most important to all is that the ethnographic research is tremendously equipped to bringing native perspective into the limelight (Denzin and Lincoln 1-17). Unlike the survey research, the issues of voice (rather "multiple voices") and (textual) representation are seriously taken into account in the ethnographic tradition (Van Maanen). Ethnographers would like to ensure that the findings are "isomorphic" (emic, local and real) and trustworthy. They make a conscious effort to having their readers "hear" their informants by giving exact narratives and words (with paralinguistic cues) (Lincoln and Guba 271).

Whereas ethnographic researches are prone to some ethical questions, the ethnographic research also entails some unique ethical and practical considerations issues that do not apply so much to the conventional and qualitatively-driven research.

\section{Ethical and Practical Issues}

Like all researchers, the ethnographers need to take responsibility for protecting research participants from harm as well as to regard their rights (Murphy and Dingwall 341; Ryen 235). Issues of anonymity, privacy and confidentiality are central to ethnographic research more than any other social inquiries (British Sociological Association 1) because ethnographic accounts are more detailed, focussed, and products of "prolonged engagement" in the field. Although harm to the researched from an ethnographer is considered to be indirect compared to other kinds of research, yet the ethnographies are not immune to it.

Participants may feel a loss of anonymity and confidentiality during public dissemination of ethnographic accounts. The use of field notes and narratives that are in "sufficient detail" will allow tracing a particular respondent or setting. Self-disclosure of the ethnographer (such as being lesbian, vegetarian, for instance) or overt reservation about one's own "positionality" might cause a detrimental effect on his/her intimacy with research participant(s). Where anonymity is maintained beyond the setting, there are still chances that members recognize themselves with each other in the narratives or descriptions (Taylor 274-282).

When ethnographic texts disrupt the assumptions of the participants, the postpublication controversies arise with complaints about distortion and/or partial representation of the reality. Finally, when times come when the ethnographer has to withdraw himself/herself from the field, his/her negligence over the promises made at a time of access negotiation may harm the participants. Even in a normal situation, participants may feel lost when the study is completed and the ethnographer prepares to withdraw (Taylor 274-282).

Following Murphy and Dingwall and Burgess, an ethnographer needs to be sensitive to those ethical, political and practical issues to protect settings and participants by removing identifying information at the earliest possible opportunity by routinely using pseudonyms and altering non-relevant details (341, 204-207). 
Having discussed some of the ethical and practical issues that are unique to ethnography, this research approach also entails some major limitations, issues that I shall turn next.

\section{Methodological Limitations}

The issue of trustworthiness in a qualitative (particularly ethnographic) research is what frequently and consistently being challenged from the quantitative corner. Findings based on qualitative research are often charged for being "sloppy" and "subjective" (Erlandson et al. 131).

In some corners of academia, there still exists a doubt that the qualitative research does not credibly fulfil rigour criteria. This is one of the main reasons for suspicion over the ethnographic approach. As critics argue, observation, for example, is not a very reliable data collection method, as different observers may record different observations. Also, the reliability of the interviews and the representativeness of the sample are put into question. Qualitative data are considered to be "anecdotal thus implausible” (Seale and Silverman 380).

On the matter of rigour criteria, authenticity and reflexivity -- more than reliability -- are the considered important for ethnographies (Seale and Silverman 379). An authentic understanding of people's realities which shapes their experience and perception is considered to be vitally important than orthodox reliability criterion. In addition, it is through the purposive sampling, open-ended questions, use of intensive verbatim records, iterative and rolling quality of fieldwork that authenticity is maintained in ethnographic and qualitative research.

\section{Conclusion}

One of the key hallmarks of ethnographic research is that it follows the interpretive approach. This applies both in humanities and social sciences. This article argues that it is the "interpretive approach" of ethnographic research that brings humanities and social sciences together in the realms of naturalistic inquiry and knowledge production. Although ethnography is conventionally considered to have originated from cultural anthropology, this interpretive approach has widely appealed the disciplines of humanities, including literary studies, professional communication and performing arts.

In this article, I attempted to delineate some of the major epistemological challenges against ethnography as posed from quantitative and postmodern corners and discussed how ethnographers would tend to address them. I also raised some of the methodological and practical utilities of the ethnographic approach, followed by a short description of ethical and practical issues involved.

The main line of my argument has been that even though ethnography is not immune to some of the limitations of qualitative research, the strengths that it offers, particularly concerning unravelling complexities of people's daily lives in their "meaning perspectives," are unique and appealing. I argue that no methodological approach other than ethnography has the potential to build "inscriptions" of the mundane detail of the everyday setting.

This article concludes that the strengths that ethnography offers, particularly concerning unravelling complexities of people's daily lives in their "meaning 
Epistemological Values and Limitations of Ethnography 89

perspectives," are unique and appealing even though ethnography never remains immune to some of the limitations of qualitative research.

\section{Works Cited}

Brewer, John David. Ethnography. Open UP, 2000.

British Sociological Association. "Statement of Ethical Practice.” BSA, 8 February 2021, www.britsoc.co.uk/equality/63.htm.

Burgess, Robert. In the Field: An Introduction to Field Research. Allen and Unwin, 1984.

Creswell, John W. Qualitative Inquiry and Research Design: Choosing Among Five Approaches. Sage Publications, 2007.

Delamont, Sara. "Ethnography and Participant Observation.” Qualitative Research Practice, edited by Clive Seale, Gobo Giampietro, Jaber F. Gubrum and David S. Silverman. Sage Publications, 2004, pp. 205-217.

Denzin, Norman K. and Yvonna Sessions Lincoln. "Introduction: The Discipline and Practice of Qualitative Research.” The Landscape of Qualitative Research, edited by Norman K. Denzin and Yvonna Sessions Lincoln, Sage Publications, 2008, pp. 1-17.

Denzin, Norman K. and Yvonna Sessions Lincoln, editors. Handbook of Qualitative Research. Sage Publications, 1994.

Emerson, Robert M., Rachel I. Fretz and Linda L. Shaw. "Participant Observation and Field Notes.” Handbook of Ethnography, edited by Paul Atkinson, Amanda Coffey, Sara Delamont, John Lofland, and Lyn Lofland, Sage Publications, 2001, pp. 352-368.

Erlandson, David A., Edward L. Harris, Barbara L. Skipper and Steve D. Allen. Doing Naturalistic Inquiry. Sage Publications, 1993.

Geertz, Clifford. The Interpretation of Cultures. Basic Books, 1973.

Hammersley, Martyn and Paul Atkinson. Ethnography: Principles in Practice. Routledge, 1995.

Lincoln, Yvonna Sessions and Egon G. Guba. "Paradigmatic Controversies, Contradictions, and Emerging Confluences.” The Landscape of Qualitative Research: Theories and Issues, edited by Norman K. Denzin, and Yvonna Sessions Lincoln, Sage Publications, 2003, pp. 253-291.

Lincoln, Yvonna Sessions and Egon G. Guba. Naturalistic Inquiry. Sage Publications, 1985.

Malinowski, Bronislaw. Argonauts of the Western Pacific. Routledge and Kegan Paul, 1922.

Marshall, Catherine and Gretchen B. Rossman. Designing Qualitative Research. Sage Publications, 1994.

Miles, Matthew B. and A. Michael Huberman. Qualitative Data Analysis: An Expanded Sourcebook. Sage Publications, 1994.

Murphy, Elizabeth and Robert Dingwall. "The Ethics of Ethnography.” Handbook of Ethnography, edited by Paul Atkinson, Amanda Coffey, Sara Delamont, John Lofland, and Lyn Lofland, Sage Publications, 2001, pp. 339-351. 
Murphy, M. Warren. "Humanistic and social scientific ethnography?” Blog, 2014, www.michaelwarrenmurphy.net/blog/humanistic-and-social-scientificethnography. Accessed 28 January 2017.

Ryen, Anne. "Ethical Issues.” Qualitative Research Practice, edited by Clive Seale, Gobo Giampietro, Jaber F. Gubrium and David S. Silverman, Sage Publications, 2004, pp. 230-247.

Seale, Clive and David Silverman. "Ensuring Rigour in Qualitative Research.” European Journal of Public Health, vol. 7, 1997, pp. 379-384.

Spradley, James P. Participant Observation. Holt, Rinehart and Winston, 1980.

Taylor, Steven J. "Leaving the Field: Research, Relationships, and Responsibilities.” Qualitative Research (Vol. 4), edited by Alan Bryman and Robert G. Burgess, Sage Publications, 1999, pp. 274-282.

Turner, Jonathan H. "In Defence of Positivism.” Sociological Theory, vol. 3, no. 2, 1985, pp. 24-30.

Van Maanen, John, editor. Representation in Ethnography. Sage Publications, 1995.

Vidich, Arthur J. and Stanford M. Lyman. "Qualitative Methods: Their History in Sociology and Anthropology.” The Landscape of Qualitative Research: Theories and Issues, edited by Norman K. Denzin, and Yvonna Sessions Lincoln, Sage Publications, 2003, pp. 55-129.

Whyte, William Foote. Street Corner Society: The Social Structure of an Italian Slum. U of Chicago P, 1981. 